\title{
Workshop Ilmu Fisika dan Aplikasinya untuk Guru Sekolah Dasar dan Menegah di Desa Oelnasi Kupang Tengah
}

\author{
Albert Zicko Johannes ${ }^{1 *}$, Jonshon Tarigan ${ }^{2}$, Minsyahril Bukit ${ }^{3}$, Zakarias S. Ngara ${ }^{4}$, \\ Hery L. Sianturi ${ }^{5}$ \\ 1,2,3,4,5 Universitas Nusa Cendana \\ *e-mail: *zickojohannes@staf.undana.ac.id
}

\begin{abstract}
In this paper, we demonstrate physical science training and its application for primary and secondary school teachers in Oelnasi Village, Kupang Regency, East Nusa Tenggara Province. Oelnasi Village is a new potential area in the development of science and technology (IPTEK) due to the availability of a national astronomical observation center in this area. The development of science and technology requires the development and improvement of knowledge related to natural phenomena. To realize this, we, Physics Lecturers at the Physics Study Program of the Faculty of Science and Technology, University of Nusa Cendana, carry out an activity to increase knowledge for elementary and junior high school teachers in Oelnasi village and around through physics training and its application. in community service activities. This activity is carried out in the form of a workshop session where the speaker provides the latest physics and development materials followed by a question and answer session. This activity can open insights and increase knowledge in the field of physics and its application for teachers.
\end{abstract}

Keywords: Oelanasi Village, physics and applications, science and technology, workshop

\section{Pendahuluan}

Undang-undang Republik Indonesia Nomor 20 Tahun 2003 tentang Sistem Pendidikan Nasional (Republik Indonesia, 2003), menyatakan bahwa pendidikan merupakan suatu usaha sadar dan terencana untuk mewujudkan suasana belajar dan proses pembelajaran agar peserta didik dapat mengembangkan potensi dirinya yang berupa: kekuatan spiritual keagamaan, pengendalian diri, kepribadian, kecerdasan, akhlak mulia, serta keterampilan yang diperlukan dirinya, masyarakat, bangsa dan Negara. Potensi diri ini merupakan dasar yang dapat digunakan sebagai bekal dalam mengikuti arus kemajuan ilmu pengetahuan dan teknologi (IPTEK) yang berkembang begitu pesat. Apabila potensi-potensi ini tidak dikembangkan berakibat pada ketidakmampuan seseorang untuk ikut terus bersaing dalam era globalisasi dan dampak lebih luasnya akan menyebabkan kemunduran dan rendahnya kualitas sumber daya manusia dalam suatu masyarakat, bangsa dan Negara.

Melalui pendidikan yang baik dan berkualitas maka potensi diri dapat berkembang secara maksimal. Dalam memenuhi pendidikan yang baik dan berkualitas ini maka perlu diperkuat unsur-unsur yang menjadi ujung tombak dari pendidikan. Unsur-unsur pendidikan ini diantaranya: peserta didik, pendidik, interaksi antara peserta didik dengan pendidik, tujuan pendidikan, materi pendidikan, alat dan metode, serta lingkungan pendidikan (Disdikpora Bulelengkab, 2017) .

Di Propinsi Nusa Tenggara Timur, unsur-unsur pendidikan ini tidak cukup kuat disebabkan adanya beberapa kendala antara lain kurangnya minat siswa/i dalam bidang ilmu dasar. Kedua kurangnya pemahaman beberapa guru sains secara umum dan aplikasinya. Ketiga masih tidak 
memadainya peralatan dan metode yang digunakan. Dan yang keempat adalah lingkungan pendidikan yang masih belum memadai.

Secara umum, kita mengalami kesulitan untuk menguatkan unsur-unsur pendidikan yang mengalami kendala secara sekaligus. Oleh karena itu, kita perlu mengarahkan perhatian ke unsur yang memegang peran besar dalam pengembangan potensi diri yaitu pendidik. Hasil penelitian oleh Fauth dkk (Fauth, et al., 2019) menunjukkan bahwa kompetensi guru berkorelasi positif dengan peningkatan prestasi peserta didik. Dalam pembelajaran sains secara umum dan fisika, maka diperlukan pendidik yang memiliki kompentensi yang baik dan pemahaman yang menyeluruh sehingga para peserta didik dapat termotivasi untuk belajar dan mencintai sains. Untuk itu direalisikan kegiatan pengabdian pada masyarakat berupa workshop pengembangan Fisika dan aplikasinya untuk para pendidik dimana kegiatan ini akan difokuskan di wilayah desa Oelnasi. Kegiatan pengabdian berupa pelatihan guru-guru ini telah sering dilakukan diberbagai penjuru Indonesia dengan bidang kajian ilmu bervariasi contohnya daerah Malang (Emaliana, 2020), Kampar Kiri Tengah (Hadiyati, Fatkhurahman, \& Suroto, 2017), Sidoarjo (Admoko \& Supriyono, 2016), Pekan Baru (Febrianis, Muljono, \& Susanto, 2014), Unggaran Barat (Ridwan, 2017), Jambi (Aina, Bambang, Retni, Afreni, \& Sadikin, 2015) dan berbagai lokasi lainnya. Hasil yang dicapai menunjukkan peningkatan kompentensi pendidik yang signifikan.

Desa Oelnasi merupakan salah satu wilayah di kecamatan Kupang Tengah, Kabupaten Kupang dengan jumlah penduduk sekitar 2.062 warga di lima dusun (Pos Kupang, 2019). Pada desa Oelnasi terdapat Bendungan Tilong (Kabupaten Kupang, 2019) yang merupakan sumber air untuk masyarakat disekitarnya dan sejak tahun 2018 telah dibangun Laboratorium Pusat Sains dan Kendali OBNAS (Langit Selatan, 2019) sebagai pusat penelitian dan edukasi sains. Berada dekat dengan lokasi Laboratorium Kendali OBNAS ini merupakan kekuatan bagi mitra (pendidik) yang berada di sekolah-sekolah di sekitar desa Oelnasi. Akan tetapi, salah satu kendala dari pendidik sebagai mitra yang mengajar di sekolah-sekolah dasar dan menengah pertama yang ada di desa Oelnasi adalah jarak antara tempat tinggal guru-guru dan sekolah tempat mereka mengajar cukup jauh. Kondisi ini menyebabkan guru-guru memiliki minat yang rendah untuk mempelajari dan memahami ilmu Fisika yang diikuti dengan terbatasnya peraatan laboratorium yang mendukung pelaksanaan eksperimen-eksperimen fisika. Oleh karena itu, melalui kegiatan pelatihan ini, diharapkan guru-guru dapat meningkatkan pemahaman pengetahuan mereka tentang ilmu Fisika dan aplikasi terbarunya sehingga mereka bersemangat kembali untuk mempelajarinya.

\section{Metode}

Metode pelaksanaan kegiatan ini adalah kegiatan workshop sehari dengan materi dan diskusi yang berkaitan dengan fisika dan aplikasinya. Pelaksanaan dan detail kegiatan pengabdian ini dibagi beberapa tahap. Berikut ini tahapan-tahapan yang dilakukan :

- Melakukan koordinasi dengan tim untuk membagi tugas dalam persiapan pelaksanaan pengabdian.

- Bertemu dengan pihak LAPAN selaku pemilik gedung-gedung di Laboratorium OBNAS untuk meminjam gedung agar pengabdian masyarakat dapat berjalan lancar.

- Menentukan waktu dan ruangan penyelenggaran pelatihan. Yaitu pada hari kamis 1 Agustus 2019, bertempat di gedung "Science Center". 
- Mengundang dan memberitahukan kepada pemateri dan mitra informasi tentang: tempat dan waktu pelaksanaan, serta agenda kegiatan. Mitra yang diundang dapat dilihat pada tabel 1 .

- Persiapan semua sarana dan prasarana kegiatan, seperti laptop, LCD serta materi. Materi yang disajikan dapat dilihat tabel 2 .

- Pelaksanaan pengabdian sesuai jadwal yang dibuat.

- Administrasi seperti dokumentasi dan daftar hadir untuk diarsip dan pembuatan laporan akhir.

- Evaluasi kegiatan pengabdian.

Tabel 1. Nama Sekolah dan jumlah guru-guru yang hadir

\begin{tabular}{lll}
\hline No & Nama sekolah & Jumlah \\
\hline 1 & SDN Oepunu & 2 orang guru \\
2 & SDN Dendeng & 3 orang guru \\
3 & SMA Kristen Pandhega Jaya & 2 orang guru \\
4 & SMPN 4 Kupang Tengah & 2 orang guru \\
5 & SMPN 3 Kupang Tengah Satu Atap & 4 orang guru \\
6 & SD GMIT Oelpuah Satu Atap & 2 orang guru \\
\hline
\end{tabular}

Tabel 2. Judul Materi yang disajikan

\begin{tabular}{lll}
\hline No & Judul Materi yang disajikan & Alokasi Waktu (Menit) \\
\hline 1 & Memahami kasih dan Murka Bumi dengan Bahasa Fisika & 30 \\
2 & Fisika Material dan Aplikasinya & 30 \\
3 & Fisika Sasando & 30 \\
4 & $\begin{array}{l}\text { Perancangan Sistem Mendeteksi Banjir Dengan } \\
\text { Menggunakan Sensor HC-SR 04 Berbasis Arduino Uno }\end{array}$ \\
\hline
\end{tabular}

\section{Hasil dan Pembahasan}

Pembahasan komponen hasil dari program pengabdian ini terdiri atas hal berikut yaitu target jumlah peserta dan target luaran yang berupa jasa dan modul. Target peserta awal yang direncanakan adalah dua peserta guru dari enam sekolah sekitar desa Oelnasi sehingga berjumlah 12 orang guru. Ketika kegiatan ini berlangsung hadir 15 orang guru (Tabel 1.). Kelebihan peserta ini menunjukkan ketercapaian jumlah target peserta. Hal ini menunjukan antusiasme guru-guru sekolah di sekitar desa Oelnasi untuk mendapat wawasan serta pengetahuan baru (Gambar 1). 
Berikutnya ketercapaian target luaran. Target luaran ini meliputi dua hal jasa dan modul. Jasa yang diberikan pada kegiatan pengabdian ini adalah berupa workshop yang berisi sharing ilmu pengetahuan dan pengalaman dengan cara ceramah dan diskusi. Pemateri menyampaikan ceramah dan diskusi sesuai dengan bidang-bidang keahlian mereka secara sangat baik yang materinya dapat dilihat pada tabel 2 . Pemateri bukan hanya menyampaikan teori dari aplikasi fisika tetapi juga memperkenalkan hasil-hasil penelitian di bidang terapan fisika yang ditampilkan melalui media pembelajaran alat peraga (Gambar 2).

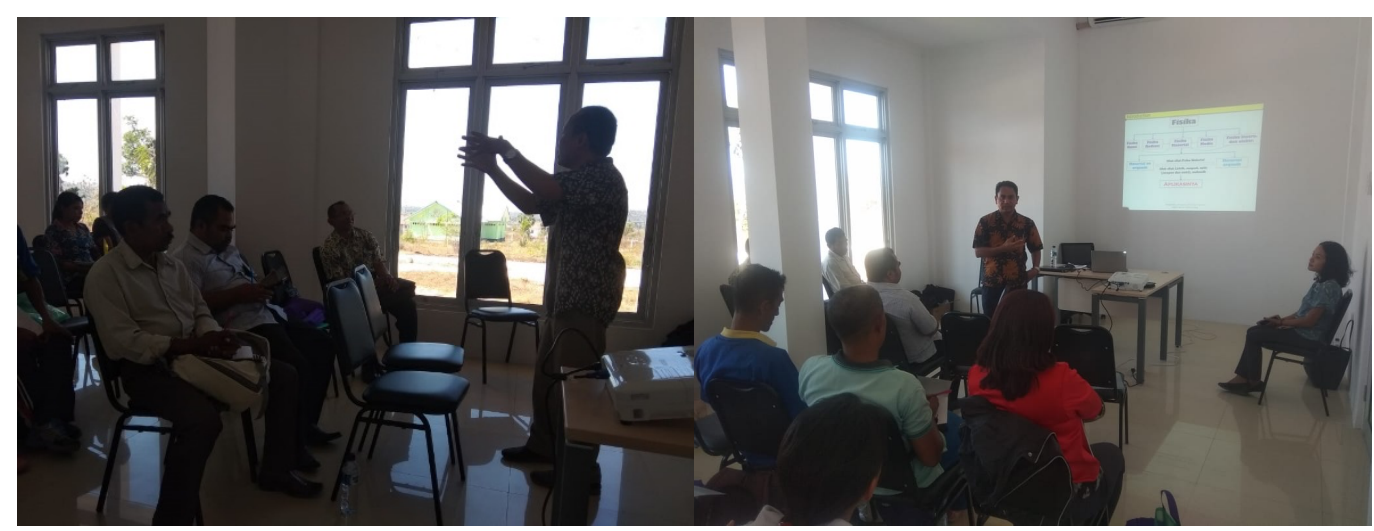

Gambar 1. Peserta sedang mendengarkan ceramah Pemateri.

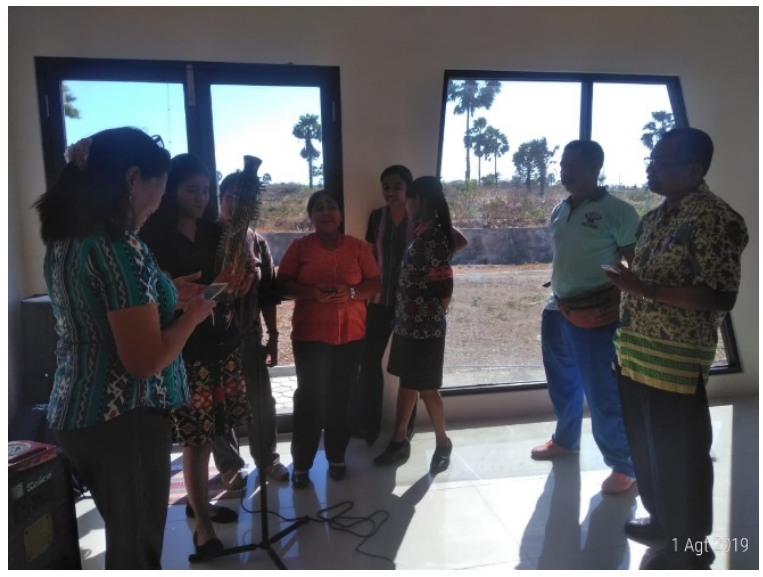

Gambar 2. Alat peraga Sasando Elektrik sebagai media pembelajaran Fisika Sasando.

Ketercapaian target luaran berupa jasa dan modul pada kegiatan pengabdian ini sangat baik. Penilaian ini hanya bersifat kualitatif karena ketercapaian ini dinilai dari komentar pemateri dan peserta setelah workshop selesai, dimana komentar yang diberikan sangat positif. Kami tidak sempat mengukur penilaian respon secara kuantitatif sebelum dan sesudah pemberian materi workshop karena keterbatasan waktu pengabdian. Selain itu penilaian ketercapaian luaran ini juga terlihat dari antusiasme peserta yang aktif memberikan berbagai pertanyaan pada saat sesi diskusi.Guru-guru peserta yang mendapat tambahan ilmu pengetahuan baru ini masih menyempatkan diri berdiskusi kembali dengan pemateri setelah kegiatan selesai dan mereka tertarik untuk mengikuti pelatihan berikutnya bila diadakan kembali. Tidak lupa juga modul dibagikan kepada peserta secara elektronik melalui Whatsapp dan email, sehingga menyempurnakan ketercapaian target luaran berupa modul. Akhir dari kegiatan ini, guru-guru, moderator dan pemateri diberikan sertifikat sebagai bukti partisipasi dalam kegiatan 
Pengabdian Pada Masyarakat ini.

\section{Kesimpulan}

Manfaat kegiatan pengabdian berupa workshop ilmu fisika dan aplikasinya untuk guru di desa Oelnasi Kupang Tengah :

1. Menambah wawasan, pengetahuan, dan ketertarikan kembali guru-guru sains terhadap bidang fisika serta menimbulkan antusias dan motivasi mengenalkan ilmu fisika dan aplikasinya di sekolahnya masing-masing. Antusiasme ini dibuktikan dengan hadirnya jumlah peserta yang melebihi target harapan.

2. Target luaran berupa jasa dan modul juga tercapai dengan sangat baik. Dimana dalam hal jasa, pemateri dapat menyampaikan semua materinya secara keseluruhan sesuai dengan bidang-bidang keahlian mereka dengan lancar dan baik. Sedangkan untuk modul, modul yang telah dibuat sebelumnya dapat dibagikan kepada pesertas secara elektronik melalui Whatsapp dan email.

\section{Referensi}

Admoko, S., \& Supriyono, S. (2016). Workshop Peningkatan Kemampuan Merancang Kegiatan Laboratorium Berorentasi pada Pendekatan Saintifik Bagi Guru Fisika Sidoarjo. Jurnal Penelitian Fisika dan Aplikasinya (JPFA), 6(1), 34-42.

Aina, M., Bambang, H., Retni, S. B., Afreni, H., \& Sadikin, A. (2015). Pelatihan penulisan karya tulis ilmiah bagi guru-guru SMA 8 Kota Jambi. Jurnal pengabdian pada masyarakat, 30(3), 29-32.

Disdikpora Bulelengkab. (2017). Unsur-Unsur Pendidikan. Retrieved April 2, 2020, from https://disdikpora.bulelengkab.go.id/artikel/unsur-unsur-pendidikan-46

Emaliana, I. (2020). Pelatihan Penulisan Karya Ilmiah bagi Guru MGMP Bahasa Inggris SMA/MA se-Malang Raya. Dinamisia : Jurnal Pengabdian Kepada Masyarakat, 3(2), 273279.

Fauth, B., Decristan, J. D., Büttner, G., Hardy, I., Klieme, E., \& Kunter, M. (2019). The effects of teacher competence on student outcomes in elementary science education: The mediating role of teaching quality. Teacher and Teaching Educaction vol. 86, 102882.

Febrianis, I., Muljono, P., \& Susanto, D. (2014). Pedagogical competence-based training needs analysis for natural science teachers. Journal of Education and Learning, 8(2), 144-151.

Hadiyati, H., Fatkhurahman, F., \& Suroto, B. (2017). Pelatihan Manajemen Penulisan Karya Tulis Ilmiah Bagi Tenaga Pendidik Di SMP N 3 Kampar Kiri Tengah. Dinamisia: Jurnal Pengabdian Kepada Masyarakat, 1(1), 122-128.

Kabupaten Kupang. (2019, Agustus 29). Bendungan Tilong. Retrieved from https://kabkupang.go.id/infowisata/bendungan-tilong/

Langit Selatan. (2019, Agustus 29). Langit Selatan. Retrieved from Langitselatan.com: https://langitselatan.com/2017/11/08/observatorium-nasional-timau/pusat-sains-tilong/

Pos Kupang. (2019, Agustus 29). 12 Tahun Warga Oelnasi Menanti Air Bersih. Retrieved from PosKupang.com: https://kupang.tribunnews.com/2011/04/15/-12-tahun-warga-oelnasimenanti-air-bersih 
Republik Indonesia. (2003). Undang-undang Republik Indonesia nomor 20 tahun 2003. Retrieved from Kelembagaan Ristekdikti: https://kelembagaan.ristekdikti.go.id/wpcontent/uploads/2016/08/UU_no_20_th_2003.pdf

Ridwan, A. S. (2017). Peningkatan Mutu Dikalangan Guru SD Gugus Diponegoro kecamatan Ungaran Barat Dengan Kemampuan Penyusunan Proposal PTK melalui Workshop. Jurnal Penjaminan Mutu, 3(1), 23-30.

\section{Ucapan Terima Kasih}

Terima kasih kepada teman-teman dosen Fisika FST UNDANA yang bersedia mendukung pendanaan pengabdian ini. Dan juga Terima kasih kepada pemateri, mahasiswa dan pegawai LAPAN Oelnasi yang telah mendukung telaksananya kegiatan ini. 